\title{
Doğuştan çarpık ayak etiyolojisi
}

\section{Congenital clubfoot etiology}

\author{
Mehmet Akif Altay, Baki Volkan Çetin
}

Harran Üniversitesi Tıp Fakültesi, Ortopedi ve Travmatoloji Anabilim Dalı, Şanlıurfa

\begin{abstract}
Bu çalışmanın amacı, okuyucuya pes (talipes) ekinovarus (PEV) etiyolojisiyle ilgili güncel bilgileri aktarmaktır. Çünkü, son gelinen noktada pes ekinovarusun etiyololojisi hala belirsizdir. Konuyla ilgili birçok araştırmacının yaptığı çok sayıdaki çalışmalarda tespit ettikleri farklı etiyolojik faktörlere rağmen, henüz tam anlamıyla tatmin edici bir sonuca ulaşılamamıştır. Çalışmalar, histopatolojik incelemeler, embriyolojik gelişimdeki aksaklıklar, genetik alt yapı çalışmaları ve sendromik birlikteliklerin incelendiği birçok açıdan yapılmıştır. Histopatolojik bulgularla ilgili genel kanı, gerçek neden olmasalar da, bunların pes ekinovarus tedavisine direnci ve devamını açıklamaya yardımcı olacağı şeklindedir. Histopatolojik değişiklikleri anlamak ve yardımcı parametreleri ortaya çıkarmak, deformitenin izleminde yardımcı olabilir. Her ne kadar dismorfik talar baş ve navikular dislokasyon fetal gelişim evrelerinde görülmüyor olsa da embriyolojik gelişim, etkilenen ekstremitede başlangıç tomurcuğunun yanlış diferansiyasyonuyla ilişkili durmaktadır. İzole PEV'in genetik alt yapıyla ilişkisini desteleyen çok sayıda yayın olmakla birlikte, henüz majör bir neden tespit edilememiştir. Pes ekinovarus, miyelodispazi, artrogripozis ve diğer birçok konjenital anomali ve sendromlarla olan birlikte olabilir; ancak, büyük çoğunlukla izole doğumsal bir defekt olup idiyopatik olarak tanımlanmaktadır. Bu makale, tüm bunlara değinirken, nerede olduğumuzla ilgili fikir vermeyi amaçlamaktadır. Etiyolojik temelin anlaşılması, pes ekinovarus için bir sınıflamanın yapılabilmesine olanak sağlayarak, hem prognoz hem de tedavi seçiminde yardımcı olacaktır.
\end{abstract}

Anahtar sözcükler: çarpık ayak; etiyoloji; talipes ekinovarus
The aim of this review is to provide the readers current information on the etiology of clubfoot. Clubfoot etiology is currently still uncertain. We have not a satisfactory conclusion although different etiological factors multiple investigators found based on several studies. Studies have done by various points of view including histopathologic analyses, arrests in embryonic development, genetic background and syndromic associations. The general consensus is that histopathological findings will help to explain the persistence of clubfoot deformity and resistance to correction, if not the actual cause. Understanding the histopathological changes that characterize clubfoot and investigating adjunctive tools for follow-up of idiopathic clubfoot may be useful. Although the characteristic dysmorphic talar head and the dislocation of the navicular have never been observed at any stage of normal fetal development, embryonic development must be present from initial limb bud differentiation in an affected extremity. A genetic basis for isolated clubfoot is supported by various studies but none of them can be considered as an exact etiological factor. Clubfoot deformity may be associated with myelodysplasia, arthrogryposis, or multiple congenital abnormalities and syndromes but is most commonly an isolated birth defect and considered idiopathic. This article aims to provide insight by addressing all these subjects. Understanding the exact etiology of clubfoot may eventually be helpful for a classification so that both prognosis and appropriate treatment methods could be improved.

Key words: clubfoot; etiology; talipes equinovarus
P EV (pes ekinovarus) 1000 canlı doğumda 1-2 arası sayıda görülen, kas iskelet sistemini ilgilendiren ve en sık görülen konjenital defekttir. PEV, ayaktan dize kadar kas iskelet sistemini oluşturan tüm dokuları (ligamentöz, osteoartiküler, muskülotendinöz ve nörovasküler) ilgilendiren konjenital bir displazidir. ${ }^{[1]}$ PEV'in yaygın görülen bir doğumsal defekt olmasıyla birlikte, hastalığın altında yatan mekanizma net değildir. İzole veya idiyopatik olgularda, bilinen bir anomali veya neden bulunamamıştır. İdiyopatik PEV patogenezi hakkında çok az şey bilinmektedir. Ayağın bu dizilim kusurunda bağlar, tendon ve eklem kapsülü gibi yumuşak doku kontraktürlerinin rolü olduğu düşünülmüş, bu nedenle, bu komponentleri içeren birçok

- Illetişim adresi: Doç Dr. Mehmet Akif Altay, Harran Üniversitesi Tıp Fakültesi, Ortopedi ve Travmatoloji Anabilim Dalı, Şanlıurfa Tel: 0505 - 4827338 e-posta: maltay63@yahoo.com

- Geliș tarihi: 25 Mayıs 2015 Kabul tarihi: 25 Mayıs 2015 
histopatolojik ve biyokimyasal inceleme yapılmıştır. Bu histopatolojik bulgular, gerçek nedeni açıklamasa da, düzeltilmeye olan direnci ve PEV' in devamlılığını açıklamaya yardımcı niteliktedir. ${ }^{[2]}$

PEV'in ilişkili olduğu çeşitli nörolojik tablolar iyi bilinmektedir. Nöromusküler hastalıklar ve sendromlarla birlikteliği nedeniyle 'idiyopatik' PEV zemininde nöromusküler veya sendromik etiyolojiden şüphelenilmiştir. Ancak, idiyopatik PEV genellikle izole bir kas iskelet sistemi deformitesi olarak görülür. ${ }^{[2]}$ Konjenital PEV için bir diğer teori, embriyolojik gelişimdeki aksaklıktır. Fetal gelişimdeki aksaklığın doğumda karşılaşılan deformiteden sorumlu olduğu öne sürülmüştür. Alt ekstremite ve ayak için fetal gelişim 6-8. haftalarda olup, idiyopatik PEV hastalarındaki ekin, supinasyon, ön ayak adduksiyonu ve talus boynunun mediyal deviyasyonu gibi birçok karakteristik özellik, bu dönemde bulunmaktadır. Ancak, dismorfik talar baş ve navikular mediyal dislokasyonun fetal gelişim sırasında görülmeyişi açıklanamamıştır. ${ }^{[2]}$

PEV, aile içinde görülmekle birlikte, tipik Mendeliyan kalıtım paternine tam olarak uymamaktadır. İkizlerde yapılan çalışmalar, farklı etnik gruplarda farklı insidanslar ve nesiller arası geçişin olması PEV'in genetik bir etiyolojik komponenti olduğunu düşündürmektedir. Yapılan tüm çalışmalar, genlerin etkisinin PEV gelişiminde küçük veya orta düzeyde olduğunu ortaya koymuş, ancak majör bir gen veya gen grubu tespit edilememiştir. ${ }^{[2]}$

Çevresel faktörler PEV'in en azından bir kısmında rol oynamaktadır. Yapılan çalışmalarda, sosyodemografik faktörler ile gebelikle ve doğumla ilgili olanlar sorgulanmış ve bunların PEV gelişimine katkısı anlaşılmaya çalışılmıştır.

Konuyla ilgili yapılan çok sayıdaki çalışmada tespit edilen farklı nedenlere rağmen, etiyolojisi henüz belirsizdir. Çalışmalar; histopatolojik incelemeler, embriyolojik gelişimdeki aksaklık, genetik alt yapı çalışmaları ve sendromik birlikteliklerin incelendiği birçok yönden yapılmıştır. Ayrıca, çevresel faktörlerin de etkili olduğu söylenmiş ve ilgili epidemiyolojik çalışmalarla, bu ortaya konulmaya çalışılmıştır. Gelecekte yapılacak daha geniş kapsamlı çalışmalarla etiyolojik temelin anlaşılması, PEV için bir sınıflamanın yapılabilmesine olanak sağlayacak, hem prognoz hem de tedavi seçiminde yardımcı olacaktır.

\section{HISTOPATOLOJIK ÇALIŞMALAR}

PEV'de deformiteyi oluşturan kaslar, bağlar, tendon, eklem kapsülü, damar ve sinir gibi yumuşak dokuların her biri incelenmiş, kontraktürlere bunlarda oluşan patolojilerin neden olduğu düşünülmüştür.
PEV'de bağ ve tendonlarda artmış kollajen lifleri ve fibroblastik hücreler gösterilmiş, doğuştan gelen sertliği açıklamak için, ayak bileği bağlarında tespit edilen myofibroblastik doku tanımlanmıştır. ${ }^{[3,4]}$ Ancak, ışıklı ve geçişli elektron mikroskopisi ile yapılan başka bir çalışmada; kapsül, fasya, bağ veya tendon kılıfının içinde myofibroblast benzeri hücreler gösterilememiştir. $^{[5]}$ PEV etiyolojisi için primer faktör olarak, retraktil fibrotik yanıt önerilmiştir. Bu hipoteze göre; yumuşak dokuda tespit edilen anormal ligamentöz ve fasiyal gerilmeler, deformitenin düzeltilmesine gösterilen direnci açıklamaktadır. ${ }^{[6]}$ Kontrakte dokuda yüksek seviyelerde TGF- $\beta$ ve PDGF gibi fibrozan faktörler tespit edilmiştir. Nötralizan antikorlarla büyüme faktör blokajı yapıldığında, kontraktür şiddetinin azaldığı ve hastalığın sonuçları üzerine pozitif etkisi olduğu raporlanmıştır. ${ }^{[7]}$ Buna karşın, PEV'in doğumsal ligamentöz laksite bulunan sendromlarla olan ilişkisi, primer etiyolojide fibrotik retraktil doku hipotezini zayıflatmaktadır. Konjenital kas lif tipinin dağılımındaki dengesizlik (Tip 1 ve Tip 2 kas lifleri arasında), özellikle peroneal ve triceps surae kaslarında, Tip 1 liflerde atrofi, histolojik spesimenlerde gösterilmiştir. ${ }^{[8]}$ PEV hastalarının sinoviyal sıvısında sinir liflerinin azalmış dansitesi, duyusal uyaranların yokluğu/eksikliği, PEV'le ilişkili fibrozis ve kontraktürlerden sorumlu tutulabilir. ${ }^{[9]}$ Ancak, tam tersine, Tip 1 liflerde indikatif özellik bulunamadığı ve PEV etiyolojisinde nöromusküler anormalliklerin sorumlu olduğu teorisini desteklemeyen yayınlar da mevcuttur. ${ }^{[10]}$

Tek taraflı PEV hastalarında, etkilenen ekstremite (baldır) çevresi etkilenmeyen tarafa göre daha küçük olup, çeşitli kaslarda kantitatif farklılıklara neden olmaktadır. Kantitatif farklılıklara rağmen, elektrofizyolojik çalışmalar ile kas ve sinirler incelenmiş ve çoğunlukla normal bulunmuş ve kas biyopsilerinin histolojik değerlendirmelerinde, PEV'li alt ekstremitelerde nonspesifik anormallikler tespit edilmiştir. ${ }^{[11]}$

PEV'de, eşlik eden dokuların (bağ, kas, tendon, kemik, eklem kıkırdağı) ortak komponenti kollajendir. Kollajen, bağ dokunun devamlılığında temel elemandır. Prolidaz, oksidatif stresten etkilenen ve kollajen yıkım basamaklarında rolü olan sitozolik bir enzimdir. Kollajen yıkımının son basamağında (hız sınırlayıcı) kilit bir rol oynayarak, kollajen biyosentezini de düzenler. Serum prolidaz aktivitesi ile oksidatif durum ilişkisinin incelendiği birçok çalışmada, kollajen metabolizmasının oksidatif stres durumuyla ilişkili olduğu ve bu ilişkinin etiyopatogenezde ve/veya hastalığın ilerleyişinde etkili olabileceği düşünülmüştür. ${ }^{[12,13]}$ Bu mantıkla düzenlenen bir çalışmada, serum prolidaz aktivitesinin ve oksidatif stresin idiyopatik PEV ile ilişkili olabileceği ileri sürülmüştür. Prolidaz aktivitesi ile oksidatif ve 
antioksidatif parametreler beraberce incelenmiştir. Oksidatif stress ile korele olarak prolidaz enzim aktivitesinde artış saptanmış ve bunun kollajen turnover'ında artışa neden olabileceği düşünülmüştür. Ancak, oksidatif stresin bu hastalıkta neden mi yoksa sonuç mu olduğu açıklanamamıştır. Çalışmanın önemli bir sonu$\mathrm{cu}$, oksidatif ve antioksidatif parametrelerin konjenital PEV'in klinik izleminde kullanılabilir olmasıdır. ${ }^{[1]}$

Tüm bu histopatolojik ve biyokimyasal çalışmalar, gerçek nedeni açıklamasa da düzeltilmeye olan direnci ve PEV'in devamını açıklar niteliktedir.

\section{EMBRIYOLOJIK ÇALIŞMALAR}

Konjenital PEV için bir diğer teori, embriyolojik gelişimdeki aksaklıktır. ${ }^{[14]}$ Alt ekstremite ve ayak için fetal gelişim 6-8. haftalarda olup, idiyopatik PEV hastalarındaki birçok karakteristik özellik bu dönemde bulunur: ekin, supinasyon, ön ayak adduksiyonu ve talus boynunun mediyal deviyasyonu. Fetal gelişimdeki aksaklığın doğumda karşılaştığımız deformiteden sorumlu olduğu öne sürülmüştür. Normal olarak supinde, adduksiyonda ve ekin pozisyonundaki ayağın sekiz haftalık emriyoda görüldüğü ve PEV'in, doğumda, yaklaşık yedi aydır intrauterin bebekte mevcut bir deformite olduğu belirtilmiştir. ${ }^{[4]}$ Ancak, gelişsim devam ederken 12-14. haftalarda, fizyolojik süreç içinde deformite düzeltilirr ${ }^{[15]}$ ve bununla beraber, diğer komponentler olan dismorfik talar baş ve naviküler mediyal dislokasyon, fetal gelişimin herhangi bir evresinde görülmemektedir. ${ }^{[16]}$ Sonuçta, normal fetal gelişimdeki aksaklık, primer displaziyi tamamen açıklayamamaktadır.

Ölü doğan PEV'lilerde yapılan çalışmalarda, kartilajinöz talar taslağın, bir primer germ plazma defekti sonucu dismorfik boyun ve naviküler subluksasyon oluşturduğu varsayılmış; normal embriyolojik gelişimde ise, dismorfik talar baş ve naviküler pozisyonun görülmemesine rağmen, etkilenen ekstremite taslağında yanlış diferansiyasyonun neticesi olabileceği düşünülmüştür. ${ }^{[17]}$

\section{GENETIK ALT YAPI ÇALIŞMALARI}

PEV etiyolojisinin multifaktöryel olduğu anlaşılmaya başlandığından beri, genetik komponentin bunun bir parçası olduğu düşünülmektedir. Bunu destekler nitelikte, tek yumurta ikizlerinde \%33 beraber görülme, olguların yaklaşık \%25'inde ailesel öykünün varlığı bulunmaktadır. ${ }^{[18]}$ Ayrıca, etnik gruplara göre PEV görülme insidansı farklılık göstermektedir. PEV, 1000 canlı doğumda 1-2 arası sayıda görülmekle beraber, Çinlilerde binde 0,39 oranıyla en düşük, Havai ve Maori popülasyonunda 1000 canlı doğumda 7 ile en yüksek oranda görülmektedir. ${ }^{[19,20]}$ İzole PEV için erkek/kadın oranı
2/1 olup, farklı etnik gruplarda bu oran değişmemiştir. Genetik mekanizma tam olarak çözümlenmiş değildir. Ancak, multifaktöriyel ve poligenik mekanizmanın sorumlu olduğu öngörülmektedir. ${ }^{[18,21]}$

Son dönemde, PEV'li hasta ve ailelerinde birçok genetik faktör incelenmiştir. Annenin gebelik süresince sigara içmesi, PEV için riski arttırmaktadır ve bu nedenle tütün kullanımından etkilenebilecek genler araştırılmıştır. Bunlar arasında $\mathrm{N}$-asetilasyon genlerini (NAT1 ve NAT2), ayrıca diğer ksenobiyotik metabolizma genlerini (örneğin, CYP1A1) takip eden çalışmaların sonuçları, bu genlerin majör bir rol oynamadığı şeklinde olmuştur. ${ }^{[22,23]}$ Diğer çalışılan genler; ekstremite ve kas morfogenezi ile ilgili (HOXA, HOXD ve IGFBP3), alt ekstremite gelişimiyle ilgili, iskelet myofibrillerinin kontraktil proteinlerini kodlayan (CAND2 ve WNT7a) genler ve art ayak spesifik geni TBX4'tür. ${ }^{[24-27]} \mathrm{Bu}$ genlerin varyasyonlarının PEV gelişimine duyarlılığı arttırmada rol oynadığı söylense de, hiçbiri doğrudan neden olabilecek derecede etkili bulunmamıştır.

Kompleks segregasyon analizleri (bir genin izole edilerek incelenmesi) sonucu, bir tek inkomplet dominant hastalık geninin, başka faktörlerinde katkısı ile inkomplet penetrasyon meydana getirdiği dile getirilmiş ${ }^{[28]}$ ve aynı analiz yöntemiyle miks resesif model önerilmiştir. ${ }^{[29]}$ Pasifik ve Maori toplumunda, bir dominant genin \%33 oranında penetrasyonu gösterilmiştir. ${ }^{[30]}$ Poligenik eşik modeli, "Carter effect" bulgusuyla desteklenmektedir. Bu modele göre, kadınlar genetik aktarım için genetik yükün daha büyük çoğunluğunu taşır. ${ }^{[31]}$ Seks dimorfizminin bu fizyolojik durumu bilinmekle beraber, erkeklerin bayanlara göre neden iki misli daha fazla etkilendiği halen anlaşılamamıştır. Seçilmiş gen yaklaşımı ile (candidate gene approach), yaygın genetik varyantlar PEV'le ilişkili tespit edilmiştir. Bunlar arasında, home domain transkripsiyon faktörleri HOXD12, HOXD13 ve kaspaz genleri bulunmaktadır. ${ }^{[32,33]}$ Ancak, bu genetik varyantların etkisi düşük olarak bulunmaktadır ve gerçek etkilerinin, yapılacak geniş çalışmalar ile desteklenmesi gerekir.

PEV etiyolojisinde tek taraflı olgular, iskelet kası kontraktil genlerini içeren hipotezi dışarda bırakmaktadır. ${ }^{[34,35]}$ Bunlar, distal artrogripozisten sorumlu tutulmakla birlikte, bunların mutasyonlarında hem alt hem üst ekstremiteyi ilgilendiren bulgular ortaya çıkmaktadır ki idiyopatik PEV'de bunlar görülmemektedir. ${ }^{[36]}$

\footnotetext{
"Yaygın hastalık-Yaygın Genetik Varyant Hipotezi"ne göre (sıklığı >\%5 olan bir alel gen üzerinde bulunan tek nükleotid polimorfizmi); sık görülen genetik varyantların her birinin PEV duyarlılığını arttırmaya küçük
} 
bir katkısı olduğu bulunmuştur. Yaygın görülen genetik varyantlar (polimorfizm); HOX homeobox genleri komşuluğunda bulunanlar, ${ }^{[32]}$ insülin like growth factor binding protein (IGFBP3), ${ }^{[24]}$ kaspaz genleri ${ }^{\left[{ }^{[3]}\right.}$ gibi, hepsi izole PEV hastalığıyla ilişkisi raporlanan genlerdir. Ancak, PEV gelişiminde tüm bu genlerin etkisi küçük olmakla beraber, PEV duyarlılı̆ındaki önemleri geniş kohort çalışmalarla ortaya konmalıdır.

Bir diğer alternatif hipotez olan "Yaygın hastalık Nadir Genetik Varyant Hipotezi"ne göre ise (<\%5 sıklığı bulunan bir alel gen üzerinde bulunan tek nükleotid polimorfizmi), her birinin PEV duyarlılığını arttırmaya orta derecede katkısı bulunmuştur. ${ }^{[38]}$ Bu hipotezi destekleyen çalışmalar içinde, erken dönem ekstremite gelişimi için kilit öneme sahip PITX1 -TBX4 transkripsiyonel yolunu araştıran çalışmalar değerlidir. PEV'li aile bireylerinde, PITX1 transkripsiyon faktöründeki nadir bir mutasyon tanımlanmıştır. PITX1, PEV için ayak deformitesini açılayan ilk gendir; özellikle art ayak ve alt vertebra gelişimindeki morfolojik değişimden sorumludur. PITX1, izole PEV'in yaygın bir nedeni değildir. Ailesel izole PEV'in yaklaşık \%5'inden sorumludur. Kromozom 17q23 lokasyonunun kopyalanma hızı, TBX4 transkripsiyon faktörüyle ilişkilidir. Bu da, PITX1 geninin transkripsiyon hedefidir. Kromozom 17q23 bölgesindeki çoğaltma ve silmelerin PEV'le sonuçlandığı ve bu nedenle TBX4 gen miktarının önemi vurgulanmıştır. PITX1 ve TBX4, ayak fenotipini belirleyen genlerdir. Bu konuda yapılacak kromozomal mikro-alan çalışmalarıyla, 17q23 kopya sayısındaki farklılıkların PEV şiddeti ve tedaviye direnç ile olan olası ilişkisinin ortaya koyulacağı öne sürülmüştür. ${ }^{[39,40]}$

Bu kompleks genetik yapı, izole PEV'in tek bir gendeki mutasyonlar yolu ile değil de multifaktöriyel ve/ veya poligenik yapıda olduğunu gösterir yöndedir.[18,21] İzole PEV'de tek bir gen geçişine karşı gelinmesindeki diğer neden, cinsiyet uyumsuzluğudur. Erkeklerde, kadınlardan daha çok görülmekle birlikte, seks kromozom geçişi bulunmamıştır. Yapılacak gen temelli tarafsız geniş çalışmalar ile, PEV'le ilişkili yatkınlığı arttıran majör ve minör genlerin tespitine ihtiyaç vardır.

\section{NÖROMUSKÜLER HASTALIKLAR VE SENDROMLARLA OLAN BIRLIKTELIK}

PEV'in ilişkili olduğu çeşitli nörolojik tablolar iyi bilinmektedir. Bunlardan en şiddetli kısmı, paralitik bozukluklarla beraberdir. Örneğin, artrogripozis ve spina bifida; bir teori olarak, nöromyojenik imbalans (özellikle peronealleri içeren) öne sürülmüştür. ${ }^{[41]}$

PEV, nöromusküler hastalıklar ve sendromlarla birliktelik gösterebilirse de, en sık izole bir doğumsal deformite ve idiyopatik olarak görülür. ${ }^{[42]}$ Yapılan çalışmaların sonuçları popülasyona bağlı olarak değişmekle birlikte, PEV'le beraber görülen konjenital anomali veya kromozomal bozukluk sıklığ \%24-50 arasında değişmektedir. ${ }^{[43,44]}$ PEV'in bilinen etiyolojileri arasında en sık sinir sistemiyle ilişkili hastalıklar olup, bunlar arasında da en yaygın olanları artrogripozis ve miyelomeningoseldir. Sinir sistemiyle olan sık ilişkisi nedeniyle; beyin, medulla spinalis, sinir ve kasları içeren nöromusküler yapının herhangi bir yerindeki aksaklık nedeniyle meydana gelmesi olasıdır. ${ }^{[45]}$

\section{ÇEVRESEL FAKTÖRLER}

PEV'in en azından bir kısmında, çevresel faktörler rol oynamaktadır. Amniyosentez ( $<13$ hafta) veya koryonvillus örneklemesinde, PEV için artmış risk bildirilmiştir. ${ }^{[46]}$ Amniyon sıvı sızıntısının neden olduğu oligohidramniyoz, özellikle ayak gelişiminin bozulmasıyla ilişkili bulunmuştur. ${ }^{[47]}$

Sigara ve tütün kullanımı, PEV için bağımsız risk faktörüdür. Geniş hasta sayısıyla yapılmış bir çalışmada; sigara için düzeltilmiş oran (OR), 1,34; aile öyküsü, 6,52; kombine oran (aile öyküsü + sigara) ise 20,30 olarak tespit edilmiştir. ${ }^{[48]}$

Yine yakın zamanda yapılmış çok merkezli epidemiyolojik araştırma sonuçlarında, PEV hastalarının çoğunluğunun primipar annelerden doğan erkek çocuklar olduğu tespit edilmiştir. Çalışma sonuçlarına göre; vücut kitle indeksi yüksek olan (BMI $\geq 30 \mathrm{~kg} / \mathrm{m}^{2}$ ) annelerde, fetal stres durumlarının ve vasküler problemlerin daha sık olduğu ve genetik geçiş durumunun daha belirgin gözlendiği bildirilmiştir. ${ }^{[49]}$

\section{SONUÇ}

PEV, büyük kısmı idiyopatik ve izole bir deformitedir. PEV ile etiyolojik açıdan elde edilen deliller artmaktadır ve etiyolojinin multifaktöriyel olabileceği yönündedir. Erken dönem ekstremite embriyolojik gelişimin genetik sıralı olarak araştırılması sonucunda, daha toparlayıcı bir etiyolojik tablo ortaya çıkacak ve bununla beraber, bu deformitenin durdurulması ve/veya düzeltilmesi için yeni tedavi şekillerinin uygulanması sağlanacaktır.

\section{KAYNAKLAR}

1. Altay MA, Erturk C, Aksoy N, Taskın A, Isıkan UE. A preliminary study pointing out the role of serum prolidase activity and oxidative-antioxidative status parameters during the treatment process of patients with idiopathic clubfoot. Scand J Clin Lab Invest 2011;71(7):576-82. CrossRef

2. Herring JA. Disorders of the foot. In: Herring JA, editor. Tachdjian's Pediatric Orthopaedics, 3rd ed. Philadelphia: W.B. Saunders; 2002. p.891-1039.

3. Ippolito E, Ponseti IV. Congenital club foot in the human fetus. A histological study. J Bone Joint Surg Am J 1980;62(1):8-22. 
4. Zimny ML, Willig SJ, Roberts JM, D'Ambrosia RD. An electron microscopic study of the fascia from the medial and lateral sides of clubfoot. J Pediatr Orthop 1985;5(5):577-81.

5. Khan AM, Ryan MG, Gruber MM, Haralabatos SP, Badalamente MA. Connective tissue structures in clubfoot: a morphologic study. J Pediatr Orthop 2001;21(6):708-12.

6. Fukuhara K, Schollmeier G, Uhthoff HK. The pathogenesis of club foot. A histomorphometric and immunohistochemical study of fetuses. J Bone Joint Surg Br 1994;76(3):450-7.

7. Li C, Nguyen Q, Cole WG, Alman BA. Potential treatment for clubfeet based on growth factor blockade. J Pediatr Orthop 2001;21(3):372-7.

8. Handelsman JE, Badalamente MA. Neuromuscular studies in clubfoot. J Pediatr Orthop 1981;1(1):23-32.

9. Ahmed M, Ahmed N, Khan KM, Umer M, Rashid H, Hashmi $\mathrm{P}$, Umar M. Sensory hypoinnervation in club foot. J Bone Joint Surg Br 2004;86(8):1163-9.

10. Herceg MB, Weiner DS, Agamanolis DP, Hawk D. Histologic and histochemical analysis of muscle specimens in idiopathic talipes equinovarus. J Pediatr Orthop 2006;26(1):91-3.

11. Bill PL, VersfeldGA. Congenital clubfoot: an electromyographic study. J Pediatr Orthop 1982;2(2):139-42.

12. Altindag $\mathrm{O}$, Erel $\mathrm{O}$, Aksoy N, Selek $\mathrm{S}$, Celik H, Karaoglanoglu $M$. Increased oxidative stress and its relation with collagen metabolism in knee osteoarthritis. Rheumatol Int 2007;27(4):339-44.

13. Altay MA, Erturk C, Aksoy N, Taskin A, Bilge A, Celik H, Isikan UE. Serum prolidase activity and oxidative-antioxidative status in Legg-Calvé-Perthes disease. J Pediatr Orthop B 2011;20(4):222-6. CrossRef

14. Boehm M. The embryologic origin of clubfoot. J Bone Joint Surg 1929;11:229-59.

15. Kawashima T, Uhthoff HK. Development of the foot in prenatal life in relation to idiopathic club foot. J Pediatr Orthop 1990;10(2):232-7.

16. Carroll NC, McMurtry R, Leete SF. The pathoanatomy of congenital clubfoot. Orthop Clin North Am 1978;9(1):225-32.

17. Adams W, Brockman EP. Congenital clubfoot. Bristol: John Wright \& Sons; 1930.

18. Lochmiller C, Johnston D, Scott A, Risman M, Hecht JT. Genetic epidemiology study of idiopathic talipes equinovarus. Am J Med Genet 1998;79(2):90-6.

19. Beals RK. Club foot in the Maori: a genetic study of 50 kindreds. N Z Med J 1978;88(618):144-6.

20. Chung CS, Nemechek RW, Larsen IJ, Ching GH. Genetic and epidemiological studies of clubfoot in Hawaii. General and medical considerations. Hum Hered 1969;19(4):321-42.

21. Wynne-Davies R. Genetic and environmental factors in the etiology of talipes equinovarus. Clin Orthop Relat Res 1972;84:9-13.

22. Hecht JT, Ester A, Scott A, Wise CA, lovannisci DM, Lammer EJ, Langlois $\mathrm{PH}$, Blanton SH. NAT2 variation and idiopathic talipes equinovarus (clubfoot). Am J Med Genet A 2007;143A(19):2285-91.

23. Sommer A, Blanton $\mathrm{SH}$, Weymouth $\mathrm{K}$, Alvarez C, Richards BS, Barnes D, Hecht JT. Smoking, the xenobiotic pathway, and clubfoot. Birth Defects Res A Clin Mol Teratol 2011;91(1):20-8. CrossRef

24. Ester AR, Weymouth KS, Burt A, Wise CA, Scott A, Gurnett CA, Dobbs MB, Blanton SH, Hecht JT. Altered transmission of HOX and apoptotic SNPs identify a potential common pathway for clubfoot. Am J Med Genet A 2009;149A(12):2745-52. CrossRef
25. Lu W, Bacino CA, Richards BS, Alvarez C, VanderMeer JE, Vella M, Ahituv N, Sikka N, Dietz FR, Blanton SH, Hecht JT. Studies of TBX4 and chromosome 17q23.1q23.2: an uncommon cause of nonsyndromic clubfoot. Am J Med Genet A 2012;158A(7):1620-7. CrossRef

26. Shyy W, Dietz F, Dobbs MB, Sheffield VC, Morcuende JA. Evaluation of CAND2 and WNT7a as candidate genes for congenital idiopathic clubfoot. Clin Orthop Relat Res 2009;467(5):1201-5. CrossRef

27. Weymouth KS, Blanton SH, Bamshad MJ, Beck AE, Alvarez C, Richards S, Gurnett CA, Dobbs MB, Barnes D, Mitchell LE, Hecht JT. Variants in genes that encode muscle contractile proteins influence risk for isolated clubfoot. Am J Med Genet A 2011;155A(9):2170-9. CrossRef

28. Rebbeck TR, Dietz FR, Murray JC, Buetow KH. A single-gene explanation for the probability of having idiopathic talipes equinovarus. Am J Hum Genet 1993;53(5):1051-63.

29. de Andrade M, Barnholtz JS, Amos CI, Lochmiller C, Scott A, Risman M, Hecht JT. Segregation analysis of idiopathic talipes equinovarus in a Texan population. Am J Med Genet 1998;79(2):97-102.

30. Chapman C, Stott NS, Port RV, Nicol RO. Genetics of club foot in Maori and Pacific people. J Med Genet 2000;37(9):680-83.

31. Kruse LM, Dobbs MB, Gurnett CA. Polygenic threshold model with sex dimorphism in clubfoot inheritance: the Carter effect. J Bone Joint Surg Am 2008;90(12):2688-94. CrossRef

32. Wang LL, Fu WN, Li-Ling J, Li ZG, Li LY, Sun KL. HOXD13 may play a role in idiopathic congenital clubfoot by regulating the expression of FHL1. Cytogenet Genome Res 2008;121(34):189-95. CrossRef

33. Heck AL, Bray MS, Scott A, Blanton SH, Hecht JT. Variation in CASP10 gene is associated with idiopathic talipes equinovarus. J Pediatr Orthop 2005;25(5):598-602.

34. Sung SS, Brassington AM, Grannatt $K$, Rutherford $A$, Whitby FG, Krakowiak PA, Jorde LB, Carey JC, Bamshad M. Mutations in genes encoding fast-twitch contractile proteins cause distal arthrogryposis syndromes. Am J Hum Genet 2003;72(3):681-90.

35. Sung SS, Brassington AM, Krakowiak PA, Carey JC, Jorde LB, Bamshad M. Mutations in TNNT3 cause multiple congenital contractures: a second locus for distal arthrogryposis type 2B. Am J Hum Genet 2003;73(1):212-4.

36. Gurnett CA, Alaee F, Desruisseau D, Boehm S, Dobbs MB. Skeletal muscle contractile gene (TNNT3, MYH3, TPM2) mutations not found in vertical talus or clubfoot. Clin Orthop Relat Res 2009;467(5):1195-200. CrossRef

37. Ester AR, Tyerman G, Wise CA, Blanton SH, Hecht JT. Apoptotic gene analysis in idiopathic talipes equinovarus (clubfoot). Clin Orthop Relat Res 2007;462:32-7.

38. Pritchard JK. Are rare variants responsible for susceptibility to complex diseases? Am J Hum Genet 2001;69(1):124-37.

39. Gurnett CA, Alaee F, Kruse LM, Desruisseau DM, Hecht JT, Wise CA, Bowcock AM, Dobbs MB. Asymmetric lower-limb malformations in individuals with homeobox PITX1 gene mutation. Am J Hum Genet 2008;83(5):616-22. CrossRef

40. Alvarado DM, Aferol $\mathrm{H}$, McCall $\mathrm{K}$, Huang JB, Techy $\mathrm{M}$, Buchan J, Cady J, Gonzales PR, Dobbs MB, Gurnett CA. Familial isolated clubfoot is associated with recurrent chromosome 17q23.1q23.2 microduplications containing TBX4. Am J Hum Genet 2010;87(1):154-60. CrossRef

41. HandelsmanJE, Badalamente MA. Club foot: a neuromuscular disease. Dev Med Child Neurol 1982;24(1):3-12. 
42. Wynne-Davies R. Family studies and the cause of congenital club foot. Talipes equinovarus, talipes calcaneo-valgus and metatarsus varus. J Bone Joint Surg Br 1964;46:445-63.

43. Bakalis S, Sairam S, Homfray T, Harrington K, Nicolaides K, Thilaganathan B. Outcome of antenatally diagnosed talipes equinovarus in an unselected obstetric population. Ultrasound Obstet Gynecol 2002;20(3):226-9.

44. Gurnett CA, Boehm S, Connolly A, Reimschisel T, Dobbs $\mathrm{MB}$. Impact of congenital talipes equinovarus etiology on treatment outcomes. Dev Med Child Neurol 2008;50(7):498502. CrossRef

45. Gordon N. Arthrogryposis multiplex congenita. Brain Dev 1998;20(7):507-11.

46. Philip J, Silver RK, Wilson RD, Thom EA, Zachary JM, Mohide P, Mahoney MJ, Simpson JL, Platt LD, Pergament E, Hershey D, Filkins K, Johnson A, Shulman LP, Bang J, MacGregor S, Smith JR, Shaw D, Wapner RJ, Jackson LG; NICHD EATA Trial Group. Late first-trimester invasive prenatal diagnosis: results of an international randomized trial. Obstet Gynecol 2004;103(6):1164-73.
47. Tredwell SJ, Wilson D, Wilmink MA; Canadian Early and Mid-Trimester Amniocentesis Trial Group (CEMAT), and the Canadian Pediatric Orthopedic Review Group. Review of the effect of early amniocentesis on foot deformity in the neonate. J Pediatr Orthop 2001;21(5):636-41.

48. Honein MA, Paulozzi LJ, Moore CA. Family history, maternal smoking, and clubfoot: an indication of a gene-environment interaction. Am J Epidemiol 2000;152(7):658-65.

49. Werler MM, Yazdy MM, Mitchell AA, Meyer RE, Druschel CM, Anderka M, Kasser JR, Mahan ST. Descriptive epidemiology of idiopathic clubfoot. Am J Med Genet A 2013;161A(7):156978. CrossRef 